\title{
Consumption of vitamin A by breastfeeding children in rural Kenya
}

Citation for published version (APA):

Ettyang, G. A., Oloo, A., van Marken Lichtenbelt, W. D., \& Saris, W. (2004). Consumption of vitamin A by breastfeeding children in rural Kenya. Food and Nutrition Bulletin, 25(3), 256-263.

https://doi.org/10.1177/156482650402500305

Document status and date:

Published: 01/01/2004

DOI:

10.1177/156482650402500305

Document Version:

Publisher's PDF, also known as Version of record

\section{Please check the document version of this publication:}

- A submitted manuscript is the version of the article upon submission and before peer-review. There can be important differences between the submitted version and the official published version of record.

People interested in the research are advised to contact the author for the final version of the publication, or visit the DOI to the publisher's website.

- The final author version and the galley proof are versions of the publication after peer review.

- The final published version features the final layout of the paper including the volume, issue and page numbers.

Link to publication

\footnotetext{
General rights rights.

- You may freely distribute the URL identifying the publication in the public portal. please follow below link for the End User Agreement:

www.umlib.nl/taverne-license

Take down policy

If you believe that this document breaches copyright please contact us at:

repository@maastrichtuniversity.nl

providing details and we will investigate your claim.
}

Copyright and moral rights for the publications made accessible in the public portal are retained by the authors and/or other copyright owners and it is a condition of accessing publications that users recognise and abide by the legal requirements associated with these

- Users may download and print one copy of any publication from the public portal for the purpose of private study or research.

- You may not further distribute the material or use it for any profit-making activity or commercial gain

If the publication is distributed under the terms of Article $25 \mathrm{fa}$ of the Dutch Copyright Act, indicated by the "Taverne" license above, 


\title{
Consumption of vitamin A by breastfeeding children in rural Kenya
}

\author{
Grace Ettyang, Aggrey Oloo, Wauter van Marken Lichtenbelt, and Wim Saris
}

\begin{abstract}
Vitamin A deficiency remains a significant health risk in developing countries, affecting infants and children in particular. To counter child malnutrition, mothers are encouraged to breastfeed to ensure that their children receive adequate macro- and micronutrients, including vitamin A. However, this assumes that the mother has sufficient vitamin $A$ intake to provide enough vitamin $A$ to her child. This study investigates maternal and infant intakes of locally available foods of high vitamin A content in a rural agricultural community in Kenya. The study aims to establish the community risk for vitamin $A$ deficiency and to assess whether breast milk is adequate to maintain and build retinol reserves of the breastfed infant. The study assesses 62 mother-child pairs and employs several methods to support its objectives, including the Helen Keller International food-frequency survey, maternal and infant anthropometric measurements, and maternal breast-milk and blood samples to determine breast-milk and serum retinol levels. We found that mothers with marginal $(<0.700 \mu \mathrm{mol} / \mathrm{l})$ serum retinol and breast-milk deficient $(<1.05 \mu \mathrm{mol} / \mathrm{l})$ in retinol accounted for $45.2 \%$ and $77.4 \%$, of our sample, respectively. A significant ( $\mathrm{p}<0.05)$ proportion $(40.3 \%)$ of mothers had breast milk deficient in retinol and marginal levels of serum retinol. The risk of vitamin $A$ deficiency in breastfed infants older than six months was high, because $89.5 \%$ of them did not consume foods high in vitamin $A$ content three times weekly. The primary source of vitamin A for infants younger than six months
\end{abstract}

Grace Ettyang and Aggrey Oloo are affiliated with the Faculty of Health Sciences, Moi University, Eldoret, Kenya. Wauter van Marken Lichtenbelt and Wim Saris are affiliated with the Department of Human Biology, Maastricht University, Maastricht, The Netherlands.

Please direct queries to the corresponding author: Ms Grace Adisa Ettyang, Department of Human Nutrition, Faculty of Health Sciences, Moi University, PO Box 4606, Eldoret, Kenya; e-mail: gaettyang@yahoo.com.

Mention of the names of firms and commercial products does not imply endorsement by the United Nations University. was breast-milk deficient in retinol vitamin A. This study suggests that in this rural community, breastfed infants may not receive appropriate foods with high vitamin $A$ content and that although exclusive breastfeeding is advocated, most breast milk is deficient in retinol, further heightening the risk of vitamin A deficiency.

Key words: Breast-milk retinol, dark-green leafy vegetables, lactation, serum retinol, vitamin A deficiency

\section{Introduction}

Vitamin A deficiency remains a significant public health problem, with an estimated 250 million children at risk worldwide [1]. Lack of data from developing countries limits the ability of governments and policy makers to quantify the magnitude of the problem in women and preschool-age children $[2,3]$. In healthy populations, less than $5 \%$ have subclinical deficiency, defined as serum retinol $<0.70 \mu \mathrm{mol} / 1$ [4]. There are concerns that a high prevalence of marginal vitamin A status may contribute to the etiology of anemia in women $[5,6]$. Hemoglobin response to iron supplementation is suppressed in those found to be deficient in vitamin A [7]. Vitamin A-deficient lactating women have been reported to produce inadequate vitamin $\mathrm{A}$ in breast milk to maintain and build body reserves in their rapidly growing infants $[4,8]$. The consequences of vitamin A deficiency in preschool-age children include increased severity of some infections [9] and an increased risk of death [10]. In populations with vitamin A deficiency, improvement in vitamin A status has reduced infant mortality rates by about $23 \%$ [11]

All infants are born with low stores of vitamin $A$ and depend on vitamin A-rich breast milk to initially accumulate and maintain adequate stores until complementary foods provide significant additional amounts of vitamin $\mathrm{A}$, in keeping with the growing child's increasing requirements. Breast-milk vitamin A concentration is therefore considered a unique indicator of maternal 
and infant vitamin A status [12]. Most retinol in breast milk is in the form of retinyl esters and is related to the fat content of breast milk $[4,7]$. Breast-milk proximate composition is relatively stable during the period from one to eight months postpartum, and its vitamin A concentration depends on maternal food intake. When diets are adequate in vitamin $\mathrm{A}$, average breast-milk concentrations for vitamin A range from 1.75 to 2.45 $\mu \mathrm{mol} / \mathrm{l}[13]$, and few mothers have breast-milk values under $1.05 \mu \mathrm{mol} / 1[4,13]$. In this ideal situation, breast milk is likely to be the major source of dietary vitamin $A$ for the infant, with complementary foods contributing little if any additional amount [4].

Breast milk is not a sensitive indicator for predicting the risk of clinical vitamin A deficiency [4]. In surveys to assess whether vitamin A deficiency is a public health problem, breast-milk data need to be supported by nutritional status and diet-related indicators [4]. In situations in which precise weighing of food intake is not feasible, general eating habits are easier to remember and are therefore more reliably reported than specific quantities of foods [4]. The Helen Keller International food-frequency questionnaire is simple and often used to identify communities at risk for low intake of vitamin $A[4,14]$. The method has been validated against serum retinol in Tanzania [15]. The questionnaire allows for incorporation of locally available key plant and animal foods that contain at least 100 retinol equivalents (RE) per $100 \mathrm{~g}$. In view of the new knowledge on the relative efficiency of carotenoids in meeting recommended vitamin A intakes, these REs may be updated in the future [16]. The seven-day foodfrequency method captures eating patterns during the course of an entire week.

In vitamin $\mathrm{A}-$ deficient women, the immediate benefits of vitamin A supplementation are not in dispute and include improvements in the vitamin A status of the breastfed infant $[7,17]$ and in maternal iron status [18]. However, supplementation alone does not improve overall community consumption patterns for foods of high vitamin A content. Developing countries with a high prevalence of vitamin A deficiency are faced with the challenge of finding community-based alternatives to single-nutrient supplementation [18]. The documented evidence on links between nutritional status at different stages of the life cycle [2] demands sustained, long-term solutions. A starting point is collection of data critical for identifying rural communities and vulnerable groups at risk for vitamin A deficiency [4]. Kenya has a scarcity of data on the vitamin A status of rural communities. The objectives of this investigation were therefore to determine whether, in a rural Kenyan agricultural community, infants and lactating women were at risk for low intake of vitamin $A$ and whether maternal breast-milk vitamin A concentration was adequate to maintain and build body reserves of the breastfed infants.

\section{Materials and methods}

\section{Study area}

This cross-sectional, population-based survey was carried out in Kokwet, a rural community located in Nandi District, between December 1998 and January 1999. This is the end of the short rains and the beginning of the dry season that ends around March, when the long rains begin. Approval for the research was obtained from both the Moi Ethical and Research Committee and the Government of Kenya. The nearest health center to Kokwet is $7 \mathrm{~km}$ away, and it provides health services to a catchment area with an estimated 5,000 households. Kokwet, with its seven villages, falls within this catchment area. The community engages in extensive large-scale maize farming. Due to the climate and zone, the maize crop planted in March and April is not harvested until October and November. The majority of farmers also keep dairy cattle. For many years, both maize and milk were important sources of income for families. This income has become more volatile because of fluctuations in maize prices and liberalization of the milk market. Traditional dark-green leafy vegetables are grown in every homestead and are abundant during the rainy season. Fruits, though not commonly grown, are seasonal and available at reasonable prices from the weekly local market.

\section{Design and subjects}

A register of lactating women in the seven Kokwet villages was compiled with the help of the assistant chief and the village elders. With a relative precision of $50 \%$, we required a minimum sample size of 47 mothers for an anticipated prevalence range of $15 \%$ to $45 \%$ breast milk $\leq 1.05 \mu \mathrm{mol} / \mathrm{l}$ ( $\leq 8 \mu \mathrm{g} / \mathrm{g}$ milkfat) [4]. In the sampling strategy we used the seven villages of Kokwet as clusters. The number of lactating women in each cluster was recorded, and a maximum of 12 lactating women were selected from each cluster. A total of 88 lactating women between the ages of 15 and 45 years, with their breastfeeding infants aged between 2 weeks and 15 months, were identified to participate in the survey. The women received a detailed explanation of the objectives and procedures of the study and gave consent to participate in the study.

Anthropometric measurements, breastfeeding patterns, and intake of key plant and animal sources of vitamin A were recorded for all of the women; however, 15 declined to provide blood and breast milk out of fear that the researchers would use the samples to test for HIV. At the time of data collection, the stigma attached to a positive HIV/AIDS status was very high. For this vitamin A intake survey, 11 infants aged $<2$ months were excluded. This avoided collection of highcolostrum breast-milk samples and ensured inclusion 
of the period when supplementary feeding was introduced to the breastfed infant. Sixty-two mother-infant pairs met this criterion and provided complete data. Of this group, 48 had infants aged 6 months and older. None of the women in this study received vitamin A supplementation.

\section{Anthropometry and collection of blood and breast milk}

Maternal body weight was measured to the nearest $50 \mathrm{~g}$ with an electronic scale (Seca) and height to the nearest $0.1 \mathrm{~cm}$ with a height meter. The body-mass index (BMI) was computed as the weight in kilograms divided by the square of the height in meters. Midupper-arm circumference (MUAC) measurements were also taken. The infant's body weight was measured to the nearest $50 \mathrm{~g}$ with a baby-weighing scale, and height was measured with a height meter. A single investigator recorded all of the measurements. Collections of 5-ml samples of serum were drawn and divided into two tubes, with and without anticoagulant. The samples were stored on ice for transportation to the laboratory. Serum was separated from the blood by centrifugation at approximately 2,000 RPM for 15 minutes at room temperature on arrival, and the samples were stored at $-70^{\circ} \mathrm{C}$ until they were analyzed for serum retinol. Milk was collected during the day from a single breast that had not been used to feed the infant for at least one hour [12]. The mothers used manual expression to collect 10 to $15 \mathrm{ml}$ of breast milk. The breast milk was stored in foiled glass bottles and transported to the laboratory in a cool box with ice packs. Two aliquots were frozen at $-70^{\circ} \mathrm{C}$, and analysis was carried out within one year of breast-milk collection.

\section{Maternal and infant intake of key vitamin A foods}

A questionnaire was used to collect data on breastfeeding patterns. Through observation, focus group discussions, and a rapid survey of the foods available at the local markets, locally available key plant and animal sources of vitamin A were then identified. Of the maximum 28 food items recommended for inclusion in the Helen Keller International food-frequency questionnaire, 11 were replaced by locally available substitutes. The selected substitute foods contained at least 100 retinol equivalents (RE) of vitamin A per $100 \mathrm{~g}[14,15]$. The modifications resulted in a foodfrequency questionnaire based on locally available key plant and animal sources of vitamin $A .^{*}$

* As a result of recent research findings, there are currently two units quantifying vitamin $A$ activity in foods. Both refer to $1 \mu \mathrm{g}$ of all-trans-retinol (vitamin A). The retinol equivalent (RE) is defined as equivalent to $6 \mu \mathrm{g}$ of dietary all-trans- $\beta$ carotene. The more recently recommended retinol activity
The survey's primary question asked for the number of times a given food item had been consumed during the previous seven days. The survey sought to determine the frequency of consumption of vitamin Acontaining food by the Nandi lactating women and their breastfed infants by using qualitative questions. The numbers of days on which dark-green leafy vegetables, yellow fruits and vegetables, and foods of animal origin were consumed were thus determined. A master table adapted to the locally available key plant and animal sources of vitamin A was used to analyze the data. From this table, the frequency of consumption of each category of food was calculated $[4,14,15]$.

The community risk for vitamin A deficiency was based on a group of nutrition- and diet-related indicators suggested by the World Health Organization (WHO) [4]. Based on infant nutritional status $[<-2$ SD WHO/National Center for Health Statistics (NCHS) growth references], the risk of vitamin A deficiency was present if the prevalence of $\mathrm{HAZ}<-2$ $\mathrm{SD}$ (stunting) was $\geq 30 \%$ or $\mathrm{WHZ}<-2 \mathrm{SD}$ (wasting) was $\geq 10 \%$. With regard to food availability, vitamin $A$ deficiency was likely to be present if dark-green leafy vegetables were unavailable in the weekly food market offerings for six or more months per year and foods of high vitamin A content were eaten less than 3 times a week by at least $75 \%$ of lactating women [4]. For infants under 6 months of age, the risk of vitamin A deficiency was present if fewer than $50 \%$ were receiving breast milk; for those aged 6 months or more, the risk was present if fewer than $75 \%$ were receiving foods of high vitamin $A$ content three times weekly in addition to breast milk [4].

\section{Biochemical analysis}

Breast-milk and serum retinol levels were assayed by high-performance liquid chromatography. Maternal vitamin A status was based on serum retinol concentration; vitamin A status was considered deficient if the retinol concentration was $<0.35 \mu \mathrm{mol} / \mathrm{l}(10 \mu \mathrm{g} / \mathrm{dl})$ and marginal if it was $<0.70 \mu \mathrm{mol} / \mathrm{l}(20 \mu \mathrm{g} / \mathrm{dl})$ [4]. The criterion for vitamin A-deficient breast milk was based on a cutoff of $\leq 1.05 \mu \mathrm{mol} / \mathrm{l}[4,12]$ with a population prevalence of $<10 \%, 10 \%-<25 \%$, and $\geq 25 \%$ used to identify vitamin A deficiency as a mild, moderate, or severe public health problem, respectively [4]. Milkfat was determined by using the field-tested [19] "creamatocrit" micromethod [20]. The percentage of cream or \% creamatic was read from the hematocrit capillary tube.

equivalent (RAE) is defined as equivalent to $12 \mu \mathrm{g}$ of dietary all-trans- $\beta$-carotene. Current food-composition research may still use the 6:1 ratio, because that is what is available in foodcomposition tables. 


\section{Data analysis}

Means and standard deviations were calculated for serum and breast-milk retinol, and percentages were calculated of the frequency of intake of key plant and animal sources of vitamin $A$. The significance of differences in proportions was determined by chi-square analysis. Pearson correlation coefficients and stepwise and backward linear regression analyses were used to determine the relationship between supposed factors related to breast-milk and maternal serum retinol. Backward regression is useful in identifying the extent to which a combination of independent variables explain the variation in a given dependent variable of interest. When applied to our data the combined intake of pumpkin, egg, and sweet potato explained $12 \%$ of the variation in breast-milk retinol. General independent variables were: infant age, maternal BMI, serum retinol, breast-milk retinol, maternal hemoglobin status, and frequency of maternal intake of key plant and animal sources of vitamin A. Two models were developed where dependent variable inclusion was set at a $p$ value of 0.05 and exclusion at 0.01 .

The SPSS software package (Windows version 11.1) was used for all statistical analyses, with a $p$ value $<0.05$ considered to indicate statistical significance.

\section{Results}

\section{Infant and maternal nutritional status}

Infant wasting (WHZ $<-2 \mathrm{SD}$ ) was not evident in this group of infants. The percentage of children stunted (HAZ $<-2 \mathrm{SD}$ ), underweight (WAZ $<-2 \mathrm{SD}$ ), and wasted ( $\mathrm{HWZ}<-2 \mathrm{SD}$ ), according to the WHO/NCHS reference, were $8.1 \%, 12.2 \%$, and $4.1 \%$, respectively (table 1). Mean maternal MUAC and BMI were within normal limits (table 1). The percentage of mothers underweight (BMI < 18.5) were $13.5 \%$. Both mean breast-milk and mean serum retinol were below 1.05 $\mu \mathrm{mol} / \mathrm{l}$ (table 1 ). The percentages of lactating women with serum retinol $<0.700 \mu \mathrm{mol} / \mathrm{l}$ and breast-milk retinol $<1.05 \mu \mathrm{mol} / 1$ were $45.2 \%$ and $77.4 \%$, respectively. The percentages of children 2 to 5 months and 6 months and older were $14 / 62(22.6 \%)$ and $48 / 62$ $(77.4 \%)$, respectively. None of these children was exclusively breastfed. For children 2 to 5 months old the risk of vitamin A deficiency was based on the percentage with breast-milk intake deficient in retinol. For children 6 months and older, the risk of vitamin A deficiency was based on the percentage with intake of breast milk deficient in retinol and with low-frequency, inappropriate, and inadequate intake of foods high in vitamin A content. The mean $( \pm \mathrm{SD}$ ) breast-milk retinol of $0.85 \mu \mathrm{mol} / \mathrm{l}(0.73 \mu \mathrm{mol} / \mathrm{l})$ observed for a
TABLE 1. Nutritional status and biochemical characteristics of 62 lactating Nandi women and their breastfed infants

\begin{tabular}{|c|c|}
\hline Measurement & Value $($ mean $\pm \mathrm{SD})$ \\
\hline \multicolumn{2}{|l|}{ Anthropometry (infants) } \\
\hline Age (yr) & $8.2 \pm 4.7$ \\
\hline Weight $(\mathrm{kg})$ & $7.63 \pm 1.64$ \\
\hline Height (cm) & $67.3 \pm 6.8$ \\
\hline Weight-for-age (Z score) ${ }^{a}$ & $-0.459 \pm 1.273$ \\
\hline Height-for-age $(Z \text { score })^{a}$ & $-0.346 \pm 2.883$ \\
\hline Weight-for-height ( $Z$ score $)^{a}$ & $0.091 \pm 1.420$ \\
\hline \multicolumn{2}{|l|}{ Anthropometry (mothers) } \\
\hline Age (yr) & $29 \pm 6$ \\
\hline Weight (kg) & $56.39 \pm 9.8$ \\
\hline Height $(\mathrm{cm})$ & $161 \pm 6$ \\
\hline $\operatorname{MUAC}(\mathrm{cm})$ & $25 \pm 3$ \\
\hline BMI & $21.3 \pm 3.2$ \\
\hline $\begin{array}{l}\text { Biochemical measurements } \\
\text { (mothers) }\end{array}$ & \\
\hline Serum retinol $(\mu \mathrm{mol} / \mathrm{l})$ & $0.693 \pm 0.264$ \\
\hline Breast-milk retinol $(\mu \mathrm{mol} / \mathrm{l})$ & $0.902 \pm 0.778$ \\
\hline$\%$ Creamatic & $4.0 \pm 2.4$ \\
\hline
\end{tabular}

MUAC, Mid-upper-arm circumference; BMI, body-mass index [weight $(\mathrm{kg}) /$ height $(\mathrm{m})^{2}$ ].

a. Based on WHO/NCHS reference for infant growth.

lactation period of 2 to 5 months was not significantly different from that of $0.92 \mu \mathrm{mol} / \mathrm{l}(0.8 \mu \mathrm{mol} / \mathrm{l})$ observed for a lactation period 6 months or more.

\section{Consumption of foods high in vitamin A content}

Although these foods were in season, the percentages of infants 6 months old or older receiving pumpkin, papaya, and yellow sweet potato once weekly were only $18.8 \%, 2.1 \%$, and $18.8 \%$, respectively (table 2 ). The percentages of mothers and children not receiving darkgreen leafy vegetables, and animal sources of vitamin A were $67.6 \%$, and $39.2 \%$, respectively, for mothers, and $77.1 \%$, and $33.3 \%$, respectively, for infants (table 2 ). The percentages of mothers and children receiving animal sources of vitamin A fewer than three times weekly were $86.5 \%$ and $89.5 \%$, respectively.

\section{Breast-milk and maternal serum retinol concentration}

The mean ( \pm SD) serum retinol levels were, respectively, $0.561(0.197) \mu \mathrm{mol} / 1$; $95 \% \mathrm{CI} 0.533,0.59$ for breast-milk retinol $<1.05 \mu \mathrm{mol} / 1$ and $2.065(0.905)$ $\mu \mathrm{mol} / \mathrm{l} ; 95 \% \mathrm{CI} 1.820,2.307 \mu \mathrm{mol} / \mathrm{l}$ for breast-milk retinol $>1.05 \mu \mathrm{mol} / \mathrm{l}$ (table 3 ). A significant $(p<0.05)$ proportion $(40.3 \%)$ of mothers with breast milk deficient $(<1.05 \mu \mathrm{mol} / 1)$ in retinol had marginal $(<0.700$ $\mu \mathrm{mol} / \mathrm{l}$ ) serum retinol (table 3 ). 
TABLE 2. Frequency of consumption of key plant and animal sources of vitamin A by lactating mothers and breastfed infants aged 6 months or more

\begin{tabular}{|c|c|c|c|}
\hline \multirow[b]{2}{*}{ Vitamin A source } & \multicolumn{3}{|c|}{ No. $(\%)$ of mothers or infants consuming source } \\
\hline & 0 days/wk & 1 day/wk & 2 days/wk \\
\hline \multicolumn{4}{|c|}{ Intake by mothers $\left(n=73^{*}\right)$} \\
\hline Dark-green leafy vegetables & $50(67.6)$ & $6(8.1)$ & $9(12.2)$ \\
\hline \multicolumn{4}{|l|}{ Yellow fruits and vegetables } \\
\hline Mango & $66(89.2)$ & $5(6.8)$ & $1(1.4)$ \\
\hline Pumpkin & $53(71.6)$ & $9(12.2)$ & $8(10.8)$ \\
\hline Papaya & $70(94.6)$ & $3(4.1)$ & \\
\hline Yellow sweet potato & $45(60.8)$ & $19(25.7)$ & \\
\hline All plants ${ }^{a}$ & $36(49.3)$ & $16(21.9)$ & $11(15.1)$ \\
\hline \multicolumn{4}{|l|}{ Foods of animal origin } \\
\hline Egg & $36(48.6)$ & $22(29.7)$ & $10(13.5)$ \\
\hline Small whole fish & $62(83.8)$ & $6(8.1)$ & $4(5.4)$ \\
\hline Liver & $67(90.5)$ & $5(6.8)$ & \\
\hline All animal sources ${ }^{a}$ & $29(39.2)$ & $26(35.1)$ & $9(12.2)$ \\
\hline \multicolumn{4}{|c|}{ Intake by infants $(n=48)$} \\
\hline Dark-green leafy vegetables & $37(77.1)$ & $6(12.5)$ & $4(8.3)$ \\
\hline \multicolumn{4}{|l|}{ Yellow fruits and vegetables } \\
\hline Mango & $38(79.2)$ & $8(16.7)$ & \\
\hline Pumpkin & $33(68.8)$ & $9(18.8)$ & $4(8.3)$ \\
\hline Papaya & $47(97.9)$ & $1(2.1)$ & \\
\hline Yellow sweet potato & $34(70.8)$ & $9(18.8)$ & $2(4.2)$ \\
\hline All plants ${ }^{a}$ & $36(49.3)$ & $16(21.9)$ & $11(15.1)$ \\
\hline \multicolumn{4}{|l|}{ Foods of animal origin } \\
\hline Egg & $18(37.5)$ & $18(37.5)$ & $11(22.9)$ \\
\hline Small whole fish & $44(91.7)$ & $3(6.3)$ & $1(2.1)$ \\
\hline Liver & $45(93.5)$ & $3(6.5)$ & \\
\hline Cod liver oil & $44(91.7)$ & $4(8.3)$ & $\therefore$ \\
\hline All animal sources ${ }^{a}$ & $16(33.3)$ & $17(35.4)$ & $10(20.8)$ \\
\hline
\end{tabular}

* Sample size is 88 ; it excludes from the 88 the 15 mothers who did not give blood samples.

a. Combined as suggested when using the HKI food frequency method [14].

TABLE 3. Concentration and distribution of serum retinol in 62 lactating Nandi women with breast-milk retinol less than and more than $1.05 \mu \mathrm{mol} / \mathrm{l}$

\begin{tabular}{|l|c|c|}
\hline \multirow{2}{*}{ Variable } & \multicolumn{2}{|c|}{$\begin{array}{c}\text { Breast-milk retinol } \\
\text { concentration }\end{array}$} \\
\cline { 2 - 3 } Serum retinol $(\mu \mathrm{mol} / \mathrm{l})$ & $<1.05 \mu \mathrm{mol} / \mathrm{l}$ & $>1.05 \mu \mathrm{mol} / \mathrm{l}$ \\
$\quad$ Mean $\pm \mathrm{SD}$ & $0.561 \pm 0.197$ & $2.065 \pm 0.905$ \\
$95 \% \mathrm{CI}$ & $0.533,0.59$ & $1.820,2.307$ \\
Frequency distribution & & \\
[no. $(\%)]$ & & \\
$<0.7 \mu \mathrm{mol} / \mathrm{l}$ & $25(40.3)$ & $3(4.8)^{*}$ \\
$0.77-1.05 \mu \mathrm{mol} / 1$ & $16(26.8)$ & $10(16.1)^{*}$ \\
$>1.05 \mu \mathrm{mol} / 1$ & $7(11.3)$ & $1(1.6)$ \\
\hline
\end{tabular}

${ }^{*} p<0.05$ (chi-square test).
Determinants of retinol in breast-milk and maternal serum

Results of an ANOVA (analysis of variance) based on stepwise regression is shown in table 4 . Breastmilk retinol as the dependent variable was related to $\%$ creamatic, explaining $23.3 \%$ of the total variation in breast-milk retinol. Controlling for breast milk $\%$ creamatic left frequency of intake of sweet potatoes as the main predictor but it explained only $7 \%$ of the variation in breast-milk retinol. Breast-milk retinol was significantly correlated with \% creamatic ( $r=0.5$; $p<0.01)$ and frequency of intake of sweet potatoes $(r=.298 ; p<0.05)$. Serum retinol as the dependent variable was related to dark-green leafy vegetables and breast-milk retinol, explaining $11 \%$ of the total variation in maternal serum retinol. Controlling for breast milk \% creamatic left dark-green leafy vegetables as the 
TABLE 4 . Effect of \% creamatic on breast-milk retinol and dark-green leafy vegetables and breast-milk retinol on serum retinol levels in 62 lactating Nandi women

\begin{tabular}{|l|c|c|c|c|c|c|}
\hline Variable & Coefficient $(b)$ & SE & $\beta$ & $p$ value & $R$ & Adjusted $R^{2}$ \\
\hline Breast-milk retinol $(\mu \mathrm{mol} / \mathrm{l})$ & & & & 0.496 & 0.233 \\
$\quad$ Constant & 0.264 & & 0.155 & 0.001 & \\
$\quad \%$ Creamatic & 0.146 & 0.033 & 0.496 & 0.000 & \\
Serum retinol $(\mu \mathrm{mol} / \mathrm{l})$ & & & & 0.377 \\
$\quad$ Constant & 0.564 & 0.007 & 0.024 & 0.313 & 0.015 & \\
$\quad$ Dark-green leafy vegetables & 0.103 & 0.050 & 0.259 & 0.043 & \\
Breast-milk retinol & & & \\
\hline
\end{tabular}

only predictor, explaining $6 \%$ of the variation in serum retinol. Serum retinol was significantly correlated with the frequency of intake of dark-green leafy vegetables $(\mathrm{r}=.287 ; p<0.05)$.

\section{Discussion}

The prevalence $(45.2 \%)$ of marginal $(<0.7 \mu \mathrm{mol} / \mathrm{l})$ serum retinol observed in the Nandi lactating women is higher than the less than $5 \%$ recommended for healthy populations [4] but similar to the $40 \%$ prevalence observed in lactating women in rural Zimbabwe [21]. With a mean BMI within acceptable limits, a significantly high proportion $(40.3 \% ; p<0.05)$ of mothers had marginal serum retinol levels and breast milk deficient in retinol. In an earlier study done to investigate their vitamin A status, iron stores, and body composition, a close relationship was found between serum retinol, hemoglobin status, and serum ferritin [22]. In a similar study that investigated micronutrient deficiencies in Indonesian lactating women, it was observed that vitamin A deficiency led to an increased risk of anemia and iron deficiency [6].

The percentages of lactating women and breastfed infants ( 6 months old or older) with no consumption of animal sources of vitamin A were $39.2 \%$ and $33.3 \%$, respectively. Despite an average lactation period of eight months, $89.5 \%$ of the breastfed infants received foods of animal origin with high vitamin A content fewer than three times weekly. Through focus group discussions, the investigators learned that breastfed Nandi infants were introduced to diluted cow's milk within the first month of life. By the age of 2 months the infants were no longer exclusively breastfed. Complementary feeding with nonmilk foods such as ripe bananas, avocado, and thin millet porridge was started from the age of two months. Unless a woman became pregnant again, breastfeeding usually continued until the child was about 18 months old. The initial pattern of breastfeeding on demand begins to be replaced by supplementary feeding made up of maize or millet porridge. As shown in this study intake of fruits and soft vegetables is likely to be low.

During the survey period, the yellow fruits and vegetables available in the market were papaya and mango, while pumpkin and sweet potato were available in home gardens. Appropriate and adequate complementary foods introduced from the age of 6 months protect breastfed infants from vitamin A deficiency $[23,24]$. The percentages of infants 6 months old or older receiving papaya and mango at least once a week were $2.1 \%$ and $16.7 \%$, respectively. Animal sources of vitamin $A$ were consumed three times a week by $10.4 \%$ of the infants.

Although they were available in the local market at reasonable prices, the least-used foods for infant supplementary feeding were papaya, small whole fish, and liver. Cod liver oil, a good source of vitamin A, was consumed at least once weekly by only $8 \%$ of the infants. Most mothers knew about cod liver oil but were unable to afford it for their infants. The risk of vitamin A deficiency in breastfed infants 6 months old or older was high, because $89.5 \%$ did not receive foods high in vitamin A three times weekly [4]. For infants less than 6 months old, the main dietary source of vitamin A was breast milk deficient in retinol. For this age group, vitamin $A$ requirements can only be met if the infants receive breast milk with retinol levels above $1.05 \mu \mathrm{mol} / \mathrm{l}[4,12]$.

The vitamin A content of breast milk is closely related to maternal vitamin A status and dietary intake of foods with high vitamin A content [25]. When lactating women have low serum retinol, breast-milk retinol tends to be low $[4,8]$. This in turn diminishes the value of breast milk as a key source of dietary vitamin $A$ for the breastfed infant. In the Nandi community, the observed high $(40.3 \%)$ prevalence of marginal serum retinol and breast milk deficient in retinol may have been due to the fact that none of the women had received any vitamin A supplementation and their intake of foods with high vitamin A content was low. This left a majority (77.4\%) of the breastfed infants 6 months old or older receiving breast milk with an inadequate retinol content $(<1.05 \mu \mathrm{mol} / \mathrm{l})$ to maintain and build their liver stores $[4,12]$. The prevalence of stunting in these breastfed infants was $12.2 \%$. At the community level it has been suggested that when the prevalence of breast-milk retinol of less than $1.05 \mu \mathrm{mol} / \mathrm{l}$ is greater than or equal to $25 \%$ and the level 
of stunting is greater than or equal to $30 \%$ in children under five years of age, then vitamin A deficiency is a potential problem of public health significance $[4,26]$. Nandi infants may not be severely stunted, but nearly a quarter of them experience growth faltering at an early age.

In addition to receiving breast milk deficient in retinol, infants 6 months old or older $(65.8 \% ; n=48 / 73)$ did not frequently receive appropriate supplementary plant and animal sources of vitamin A. A study investigating infant-feeding practices in Kenya, Mexico, and Malaysia reported that though Kenyan mothers continued to breastfeed for up to 12 months, early supplementation of their breastfed infants with milk and/or other foods was a common practice [27]. In our study population, all infants were breastfed on demand. Breast-milk retinol concentration was found to be low regardless of the duration of lactation. On the other hand, a study investigating factors influencing vitamin A status of lactating Bangladeshi women observed that women with a lactation period of at least six months had significantly lower serum vitamin A levels than women with a lactation period of less than six months. Duration of lactation had an important influence on the vitamin A status of the women [28].

In our study population, $\%$ creamatic was identified as a predictor of breast-milk retinol, but when $\%$ creamatic was controlled for, intake of sweet potatoes became the main predictor. In turn, dark-green leafy vegetables and breast-milk retinol were the main predictors of serum retinol. Sweet potatoes are a popular snack food and are generally available throughout the year. All homesteads plant dark-green leafy vegetables that are abundant only during the rainy season. A study investigating vitamin A deficiency in rural lactating Zimbabwe women also found dark-green leafy vegetables to be the main source of vitamin A. Retinol-containing foods and yellow fruits and vegetables were rarely consumed. In these women, vitamin A and iron deficiencies were identified as problems of public health significance [21]. Similarly, in lactating Bangladeshi women, intake of vitamin A was identified as a predictor of breast-milk retinol [28].

We did not obtain data on the prevalence of clinical vitamin A deficiency in the breastfed infants. The mothers were not willing to let us draw blood from their infants, and accurate assessment of infant morbidity was not possible. The theoretical cutoff of breast-milk retinol $<1.05 \mu \mathrm{mol} / \mathrm{l}$ has not been confirmed locally but is based on observations made in a population of mothers in central Java, Indonesia. To carry out a three-day precise weighing dietary assessment with biochemical analyses of serum and breast milk posed important financial, logistical, and technical constraints. This limited our sample size to 88 lactating mother-infant pairs. We found the Helen Keller Inter- national food-frequency method simple and fast to use. The data collected, though not quantitative, proved to be useful in assessing community risk for low intake of vitamin $\mathrm{A}$-rich foods.

In summary, despite adequate local availability, mothers and children did not frequently receive foods high in vitamin A content. This low intake requires nutritional improvement, as is supported by the biochemical findings among this group of lactating Nandi women. With the apparently low serum retinol during a period of abundance of foods high in vitamin A content, the Nandi women studied may not be able to maintain an optimal vitamin A status during lactation. This may diminish the importance of breast milk as a dietary source of vitamin A for the breastfed infant. This study suggests that increasing vitamin A intake in women of childbearing age may be adequate to ensure that young children receive sufficient amounts of vitamin A. For this study, the low intake of foods high in vitamin $A$, combined with the high prevalence of marginal serum retinol and breast milk deficient in retinol, identifies vitamin A deficiency as a problem of public health significance for the Nandi community.

\section{Recommendations}

Baseline data for monitoring change in vitamin A status over time have been provided, and a modified food-frequency questionnaire that will prove useful in monitoring the impact of community-based vitamin A deficiency interventions has been developed. As a determinant of breast-milk retinol, the \% creamatic method is recommended as a simple and easy technique for assessing improvements in breast-milk vitamin A. We recommend that intervention strategies involve a mix of measures that will result in improved vitamin A status. For a long-term permanent solution to the problem, we recommend food-based approaches. To increase the dietary intake of vitamin A-containing foods by vulnerable groups, nutrition and social marketing interventions should be considered.

\section{Acknowledgments}

This study was supported by the MUNDO Moi University and Maastricht University project. I am grateful for the facilitation role played by the Dean Prof. B. O. Khwa-Otsyula and the former Dean of the Faculty of Health Sciences, Prof. H. N. K. arap Mengech. Special thanks go to the assistant chief and the Nandi women of Kokwet. We also give special thanks to Mr. L. C. Kimile for assistance in sample collection and the KEMRI labs for support in sample analysis. 


\section{References}

1. Global prevalence of vitamin A deficiency. Micronutrient Deficiency Information System (MDIS) Working Paper No. 2; 1995 Geneva: World Health Organization WHO/NUT/95.3.

2. Fourth report on the world nutrition situation. Nutrition throughout the life cycle. 2000; Geneva: ACC/SCN in collaboration with IFPRI.

3. Gross R, de Romana GL, Tomaro J. A life-cycle approach to multi-micronutrient supplementation: rationale and programme concept. Food Nutr Bull 2000;21:270-4.

4. World Health Organization. Indicators for assessing vitamin A deficiency and their application in monitoring and evaluating intervention programmes. World Health Organization . Geneva;1996. WHO/NUT/96.10.

5. Role of vitamin A in iron deficiency anemia. New York: Raven Press. Nestlé Nutrition Workshop Series 1992; Vol 30. 93-101.

6. Dijkhuizen MA, Wieringa FT, West CE, Muherdiyantiningsih, Muhilal. Concurrent microntrient deficiencies in lactating mothers and their infants in Indonesia. Am J Clin Nutr 2001;73:786-91.

7. Safe vitamin A dosage during pregnancy and lactation. The micronutrient initiative. World Health Organization. Geneva; 1998. WHO/NUT/98.

8. Underwood BA. Maternal vitamin A status and its importance in infancy and early childhood. Am J Clin Nutr 1994;59(2 suppl):517S-22S.

9. Hussey G, Klein M. A randomized, controlled trial of vitamin $A$ in children with severe measles. $N$ Engl J Med 1990;323:160-4.

10. West KP Jr, Pokhrel RP, Katz J, LeClerq SC, Khatry SK, Shrestha SR, Pradhan EK, Tielsch JM, Pandey MR, Sommer A. Efficacy of vitamin A in reducing preschool child mortality in Nepal. Lancet 1991;338:67-71.

11. Effectiveness of vitamin A supplementation in the control of young child morbidity and mortality in developing countries. Nutrition Policy Discussion Paper No. 13; 1993; ACC/SCN.

12. Stoltzfus RJ, Underwood BA. Breast-milk vitamin A as an indicator of the vitamin A status of women and infants. Bull World Health Organ 1995;73:703-11.

13. Newman V. Vitamin $A$ and breast-feeding: a comparison of data from developed and developing countries. Food Nutr Bull 1994;15:161-76.

14. Rosen D, Haselow N, Sloan N. How to use the HKI food frequency method to assess community risk of vitamin A deficiency. HKI Vitamin A Technical Assistance Program. 1993. New York.

15. Sloan N, Rosen D, de la Paz T, Arita M, Temaliwa C, Solomons $\mathrm{N}$. Identifying areas with vitamin A deficiency: the validity of a semiquantitative food frequency method. Am J Public Health 1997;87:186-91.
16. Bender DA. The Vitamins. In: Introduction to human nutrition. Gibney MJ, Vorster HH, Kok FJ, eds. Oxford, UK: Blackwell Publishing; 2002:125-32.

17. Stoltzfus RJ, Hakimi M, Miller KW, Rasmussen KM, Dawiesah S, Habicht JP, Dibley MJ. High dose vitamin A supplementation of breast-feeding Indonesian mothers: effects on the vitamin A status of mother and infant. J Nutr 1993;123:666-75.

18. Muslimatun S. Nutrition of Indonesian women during pregnancy and lactation; a focus on vitamin $A$ and iron. PhD thesis, Wageningen University, The Netherlands, 2001.

19. Prentice A, Prentice AM, Whitehead RG. Breast-milk fat concentration of rural African women. 1. Shortterm variations within individuals. Br J Nutr 1981;45: 483-94.

20. Lucas A, Gibbs JA, Lyster RL, Baum JD. Creamatocrit: simple clinical technique for estimating fat concentration and energy value of human milk. Br Med J 1978;22: 1018-20.

21. Ncube TN, Malaba L, Greiner T, Gebre-Medhin M. Evidence of grave vitamin A deficiency among lactating women in the semi-arid rural area of Makhaza in Zimbabwe. A population-based study. Eur J Clin Nutr 2001;55:229-34.

22. Ettyang GA, van Marken Lichtenbelt WD, Oloo A, Saris WHM. Serum retinol, iron status and body composition of lactating women in Nandi, Kenya. Ann Nutr Metab 2003;47:276-83.

23. Mahalanabis D. Breast feeding and vitamin A deficiency among children attending a diarrhoea treatment center in Bangladesh: a case-control study. Br Med J 1991;303: 493-6.

24. Brown KH, Akhtar NA, Robertson AD, Ahmed MG. Lactational capacity of marginally nourished mothers: relationships between maternal nutritional status and quantity and proximate composition of milk. Pediatrics 1986;78:909-19.

25. Allen LH. Maternal micronutrient malnutrition: effects on breast milk and infant nutrition and priorities for intervention. SCN News 1994, No. 11.

26. de Onis M, Monteiro C, Akre J, Glugston G. The worldwide magnitude of protein-energy malnutrition: an overview from the WHO Global Database on Child Growth. Bull World Health Organ 1995;71:703-12.

27. Diamond HJ, Ashworth A. Infant feeding practices in Kenya, Mexico and Malaysia. The rarity of the exclusively breast-fed infant. Hum Nutr Appl Nutr 1987;41:51-64.

28. Ahmed F, Azim A, Akhtaruzzaman M. Vitamin A deficiency in poor, urban, lactating women in Bangladesh: factors influencing vitamin A status. Public Health Nutr 2003;6:447-52. 